\title{
HISTORIA Y MATEMÁTICAS INTEGRADAS \\ A TRAVÉS DE UN DIAGRAMA METODOLÓGICO
}

\author{
Miguel Chaquiam \\ miguelchaquiam@gmail.com \\ Universidade do Estado do Pará
}

Recibido: 06/12/2019 Aceptado: 02/02/2020

\begin{abstract}
Resumen
La propuesta presentada surge de las preocupaciones de enseñar el curso de Historia de las Matemáticas en el curso de pregrado en Matemáticas, en 2005, y estudios relacionados con el doctorado, de 2009 a 2012, y evaluado en el curso de posgrado al enseñar el curso de Historia de las Matemáticas. como recurso didáctico. Después de revisar la literatura sobre el uso de la historia en la enseñanza y varios estudios empíricos utilizando el diagrama de pregrado y posgrado, cuyos resultados rentables fueron expuestos en libros, inicialmente en 2015, reestructurados en 2016 y refinados en 2017, me propuse presentar el diagrama, reflexiones sobre el texto marcado por el diagrama y el público objetivo, así como ejemplos y percepciones de los estudiantes sobre el diagrama. Los experimentos señalan que el diagrama puede ser un elemento guía importante en la composición de textos que relacionan la historia y las matemáticas en función de la elección del tema/contenido. Además, la composición del diagrama se ha configurado como un espléndido ejercicio de investigación en la búsqueda de información en diversos contextos $\mathrm{y}$, más aún, la composición textual se ha convertido en un ejercicio admirable ante la necesidad de articular y dar forma a diferentes coyunturas y contenidos en el mismo.
\end{abstract}

Palabras clave: Historia de las matemáticas. La historia como recurso didáctico. Historia de la enseñanza de la matemática. Elaboración de textos con Historia y Matemáticas.

\section{HISTORY AND MATHEMATICS INTEGRATED THROUGH A METHODOLOGICAL DIAGRAM}

\begin{abstract}
The proposal presented emerges from the concerns of teaching the History of Mathematics course in the undergraduate course in Mathematics, in 2005, and studies related to the doctorate, from 2009 to 2012, and appraised in the postgraduate course when teaching the course History of Mathematics. as a didactic resource. After reviewing the literature on the use of history in teaching and various empirical studies using the undergraduate and postgraduate diagram, which profitable results were exposed in books, initially in 2015, restructured in 2016 and refined in 2017, I set out to present the diagram, reflections about the text marked by the diagram and the target audience, as well as example and students' perceptions of the diagram. Experiments point out that the diagram can be an important guiding element in the composition of texts that relate history and mathematics based on the choice of theme/content. Moreover, the composition of the diagram has been configured as a splendid research exercise in the search for information in various contexts and, more, the
\end{abstract}


textual composition has become an admirable exercise in the face of the need to articulate and shape different conjunctures and contents in the same.

Keywords: History of Mathematics. History as a didactic resource. History for Mathematics Teaching. Text Writing with History and Mathematics.

\title{
HISTÓRIA E MATEMÁTICA INTEGRADAS POR MEIO DE UM DIAGRAMA METODOLÓGICO
}

\begin{abstract}
Resumo
A proposta apresentada emerge a partir das inquietações ao ministrar a disciplina História da Matemática no curso de licenciatura em Matemática, em 2005, e de estudos relativos ao doutoramento, de 2009 a 2012, e aquilatada na pós-graduação ao ministrar a disciplina História da Matemática como recurso didático. Após revisões da literatura sobre o uso da história no ensino e de diversas empirias utilizando o diagrama na graduação e na pósgraduação, cujos resultados proveitosos foram expostos em livros, inicialmente em 2015, reestruturados em 2016 e afinados em 2017, estabeleci como objetivo apresentar o diagrama, reflexões acerca do texto balizado pelo diagrama e do público alvo, bem como exemplo e percepções de alunos em relação ao diagrama. As experimentações apontam que o diagrama pode ser um importante elemento balizador na composição de textos que relacionam história e matemática a partir da eleição de tema/conteúdo. Além disso, a composição do diagrama tem se configurado como um esplêndido exercício de pesquisa na busca de informações em diversos contextos e, mais, a composição textual tem se tornado um admirável exercício frente a necessidade de se articular e amoldar diferentes conjunturas e conteúdos num mesmo texto.
\end{abstract}

Palavras-chave: História da Matemática. História como recurso didático. História para o Ensino de Matemática. Elaboração de texto com História e Matemática.

\section{INTRODUÇÃO}

Esse constructo nasce da necessidade de se organizar didaticamente a disciplina de História da Matemática nos cursos de graduação e pós-graduação e do surgimento de um esboço do diagrama a partir de empirias diversas onde se procurava agregar história da matemática, conceitos matemáticos e personagens. Vislumbrado a possibilidade de melhoria desse esboço, debruço-me sobre o desafio de se construir um modelo estrutural que contemple uma visão histórica, e até crítica, da Matemática ao longo da evolução de conceitos matemáticos, associada a personagens e com possíveis interconexões com o seu ensino.

O diagrama metodológico orientador destaca o saber matemático numa dinâmica multifacetada estabelecendo conexões pluridisciplinar e sociocultural, além disso, explora os conteúdos a partir da produção de um personagem, conectando esse personagem a alguns 
contemporâneos seus, adotando como referência a tríade contextual nos aspectos sociocultural, pluridisciplinar e técnico-cientifico.

A proposta descrita não está endereçada aos historiados de profissão ou matemáticos com experiência em história da matemática, mas, sim, aos que se encontram em formação inicial e professores em geral, com pouca ou sem nenhuma experiência na elaboração de textos com esse viés, tendo em vista aproxima-los da história, em especial, da história da matemática, e com o intuito de apresentar um entrelaçamento entre história e matemática com possibilidades de uso do texto resultante como recurso didático no ensino de matemática.

Por meio dessa proposta é possível destacar temas ou conceitos matemáticos que são frequentemente debatidos, muitas vezes reforçados desde a educação básica, mais também valorizar trabalhos subsidiários e seus autores. Escrever recortes da história da matemática com esse viés visa aproximar estudantes e professores da matemática e de sua história. Por outro lado, a composição do texto nos fornece uma espécie de catálogo de fatos da história geral, em especial da matemática, organizados temporalmente de acordo com a evolução dos temas e personagens associados a estes.

Em relação aos cursos de formação de professores identificam-se em suas estruturas curriculares disciplinas que possibilitam certa aproximação com a história da matemática, assim como, mais recentemente com a história da educação matemática. Embora Moura e Silva (2014, p. 336) argumentem que "incorporação de conteúdos históricos no ensino tem sido considerada importante por seu potencial em contribuir para a melhoria do aprendizado de conceitos e ideias científicas e para uma formação cultural ampla dos indivíduos", observase em diversos estudos que pouco efeito tem causado na formação do futuro professor, ou seja, esses componentes contribuem pouco à compreensão do viés histórico e, mais, pouco incentiva a inserção da história em suas atividades profissionais.

Concordamos com Moura e Silva (2014, p. 337) quanto ao fato de que história pode "fornece subsídios para compreender como a ciência é produzida, como os cientistas trabalham e quais são as influências sofridas e exercidas por eles, afastando concepções ingênuas e distorcidas sobre o processo de construção do conhecimento científico". Por outro lado observa-se que predomina certo marasmo, que se prefere manter um discurso autoritário a partir de um conjunto de verdades absolutas, apoiados por lamentos pela carência de materiais didáticos disponíveis para tal finalidade, do que enveredar por caminhos para sair da zona de 
conforto, lidar com desafios, definir novas metas, conquistar novos objetivos e incorporar a história como um recurso didático no ensino, em particular, no ensino de matemática.

$\mathrm{O}$ que um iniciante pode imaginar ao se deparar com informações que ressaltem um personagem e suas contribuições para o desenvolvimento da ciência ou quando são desnudas suas fraquezas? Ou ainda, como despertar em iniciantes com pouco arcabouço matemático, desenvolturas reduzidas na elaboração de textos que integrem história e matemática ou experiência profissional mínima o gosto pela história e contribuir para o desenvolvimento de um sentido histórico?

Esta proposta, muito provavelmente, não é uma forma muito significativa de bordar a história sob o ponto de vista de historiadores de ofício numa perspectiva atualizada. Aqui, nossos interesses são bem diferentes das dos historiadores profissionais. Esse esforço intelectual também funciona no sentido de promover descobertas e métodos associados a personagens, nem sempre tão conhecidos no mundo acadêmico, e aclarar diante de nossos olhos "amostras" de trabalhos matemáticos de primeira linha em suas épocas e seus idealizadores.

Sob outro ponto de vista, pode fornecer certo "caminho" para investigar a interação entre os diversos contextos que integram o diagrama. Também pode servir de inspiração ao iniciante, seja tomando de modelo o trabalho de antepassados ou pela aproximação da matemática e sua história, que de certo modo é função do professor com algum senso de história apresentá-los.

O uso do diagrama proposto orienta a elaboração de um texto que contempla uma abordagem multicontextual, proporciona a integração da história e matemática e fornece uma visão global aos iniciantes da historicidade do conhecimento científico. Não é foco principal a elaboração de um texto temático nos moldes que parametrizam vertentes historiográficas atualizadas, mais fazer uso de textos elaborados com esse viés na composição do texto baseado no diagrama. Nessa proposta não estamos apenas visando o desenvolvimento de "temas" interessantes, não apenas por sua estética matemática, mas também para que a arte da descoberta seja promovida.

Não há intensão em reforçar vertente historiográfica tradicional, de reforçar a necessidade do desenvolvimento do tema/conceito numa perspectiva evolucionista linear e 
presentista do conhecimento, tão pouco enfatizar que fatos correlacionados ao longo da história (passado) contribuíram para as etapas mais aprimoradas do conhecimento (presente).

Ressalto que nessa proposta não é feito uma simples "justaposição cronológica" de história e matemática para obtenção do texto final e, nesse sentido, de certo modo essa proposta vai de encontro ao proposto por Saito e Dias (2013) quanto ao localizar um objeto matemático e, tomado por sua episteme, revelar as diversas conexões que dão sentido a sua existência naquele contexto histórico e gerar possibilidades para exploração pelos educadores matemáticos, dando ênfase maior ao contexto no qual esses conceitos foram desenvolvidos.

Um requisito indispensável é o uso adequado de linguagens - materna e matemática bem como a fiabilidade das fontes, princípio básico da pesquisa em história, principalmente quando as fontes primárias não estiverem disponíveis, muito embora, este trabalho não requeira o uso de originais em face da natureza dos textos a serem elaborados e seus propósitos.

Para um iniciante é difícil reconhecer e compreender ideias matemáticas e, muito mais, rastreá-las sob muitos disfarces antes de emergirem, bem como traçar suas consequências, fatos que podem gerar anacronismos, falta de alinhamento das informações ao retratar ocorrências de uma determinada época noutro período. Nesse sentido concordamos com Saito e Dias (2013, p. 96) quando afirmam que "ao introduzirmos a história no ensino de matemática, corremos o risco de acentuar o anacronismo existente nas várias histórias da matemática. Esse anacronismo consiste em atribuir, a um estudioso de matemática do passado, posturas e atitudes conscientes que ele nunca possuiu".

Considerando o público a quem se destina a proposta e considerando o questionamento apresentado por André Weil durante sua conferência no International Congress of Mathematicians, Helsinki, em 1978: "Quanto conhecimento matemático deve-se possuir para lidar com a história da matemática?" e tomando por base a constituição do diagrama e as características do texto a ser elaborado, questiono: Quanto conhecimento matemático deve possuir um iniciante para lidar com os diversos contextos que compõe o diagrama e elaborar um texto entrelaçando história e matemática, inclusive para fins didáticos?

Concordo com André Weil quando afirmar que para um melhor entendimento de um determinado tema/assunto é necessário que esse conhecimento ultrapasse o período demarcado, que é necessário compreender que de ideias "rudimentares" do passado frequentemente 
emergem conceitos é métodos no futuro. Entretanto, em nosso caso, observa-se que o público alvo detêm conhecimentos com pouca profundidade sobre as temáticas mais recorrentes, a exemplo do conceito de função, trigonometria, cálculo diferencial e integral, matrizes e etc., uma vez que estamos lidando com iniciantes ou alunos da licenciatura no desenvolvimento da disciplina história da matemática, componente curricular constante nos últimos semestres dos cursos de licenciatura em matemática. Para além dos conhecimentos relacionados aos conceitos matemáticos, devem também ter conhecimentos de história geral preconizado para a educação básica.

$\mathrm{Na}$ composição dos contextos integrantes do diagrama não é objetivo identificar as ideias iniciais, rastreá-las, analisar suas influências ou caracterizar onde se tornaram obstáculos nos desenvolvimentos subsequentes, mas, é de bom tom identificar trabalhos realizados por especialistas que apresentem tais fatos e, a partir destes, selecionar recortes de modo que possam ser explorados dentro de um contexto didático-pedagógico como recurso didático.

Ressalto que também houve contribuições dos integrantes do Grupo de Pesquisa em História, Educação e Matemática na Amazônia (GHEMAZ) a partir das discussões correlacionadas aos contextos que compõe o diagrama, bem como a elaboração de um texto numa perspectiva didático-pedagógica, considerando as possíveis dificuldades quanto a disponibilidade de materiais e a pouca experiência do público alvo.

\section{DA CONSTITUIÇÃO DO DIAGRAMA A ELABORAÇÃO DO TEXTO}

Discorro de forma abreviada os primeiros passos a partir da indicação do Departamento de Matemática para ministrar História da Matemática no curso de Licenciatura em Matemática em 2005. Ultrapasso esse desafio frente a alunos com pouco ou quase nenhum embasamento sobre história matemática, ciências ou pesquisa em história e introduzo leituras que foram de encontro a aquelas constantes nos livros técnicos de matemática.

Novos questionamentos surgiram quanto ao desenvolvimento da disciplina História da Matemática depois de uma tentativa de desenvolvê-la por meio de seminários que contemplassem tópicos da matemática, visto que as apresentações se constituíram fundamentalmente nas leituras dos slides contendo recortes de textos de livros ou artigos e, principalmente, informações obtidas na internet. 
Posteriormente, após a leitura de textos pré-selecionados, iniciei debates sobre como a História de Matemática pode contribuir para o processo de ensino e de aprendizagem dos conteúdos matemáticos e, considerando a experiência obtida pela participação na avaliação de livros didáticos de matemática da educação básica, propus que fossem efetuadas análises de livros didáticos quanto ao uso da história da matemática como estratégia facilitadora no processo de ensino e aprendizagem dos conteúdos matemáticos.

A criação da coleção Trilhos da Matemática - composta inicialmente por vinte quadros e exposta na Galeria de Artes Graça Landeira, em 2006 - se deu a partir dos trabalhos desenvolvidos pelos alunos do curso de licenciatura em Matemática, os quais contemplavam personagens pré-selecionados que contribuíram para o desenvolvimento da matemática ao longo do tempo, sendo obrigatório apresentar o nome completo e sua árvore genealógica, quando fosse possível identificar sua genealogia; pseudônimo, quando fosse o caso; traços biográficos e acadêmicos; trabalhos produzidos, com ênfase aos mais relevantes e/ou soluções de problemas internos à própria matemática ou áreas afins; identificação de contemporâneos de outras áreas do conhecimento científico; frases célebres, curiosidades e fotografias em geral, dentre outros itens. Em decorrência da repercussão positiva frente alunos e professores que visitaram a exposição, a coleção foi aceita para exposição no IX Encontro Nacional de Educação Matemática (IX ENEM), realizado em Belo Horizonte (MG), em 2007, cujo conjunto era composto por trinta e seis quadros.

Os estudos relacionados ao uso da história da matemática como recurso didático foram intensificados a partir da maior aproximação com a Sociedade Brasileira de História da Matemática (SBHMat), em 2007, com realização do VIII Seminário Nacional de História da Matemática (VIII SNHM), em Belém do Pará, em 2009, da coordenação dos Encontros Paraenses de Educação Matemática (EPAEM), em 2010 e 2011, este último sob a temática Faces da História da Matemática e da Educação Matemática na Amazônia.

No XI ENEM de 2013, durante a participação na mesa Propostas práticas de uso didático da História da Matemática na Educação Básica, apresento a primeira versão do diagrama e proponho o ensino de conteúdos matemáticos e de história da matemática a partir de personagens/matemáticos. No XI SNHM em 2015, após experimentações e recomposições do diagrama, reapresento a proposta no livro História da Matemática em sala de aula: proposta para integração aos conteúdos matemáticos, onde destaco que modelo base do 
diagrama metodológico poderá balizar a elaboração de um texto envolvendo tópicos de história da matemática associada a personagens/matemáticos e tema/conteúdos ministrados em salsa de aula.

Em 2016, após apresentação e discussões em torno do diagrama e dos exemplos gerados a partir deste no II Seminário Cearense de História da Matemática (II SCHM), no curso de mestrado profissional em Ensino de Matemática e no grupo de pesquisa em História, Educação e Matemática na Amazônia (GHEMAZ), adicionado minhas reflexões e contribuições a respeito dos debates ocorridos, apresento outra versão do diagrama, onde foram delimitados os contextos técnico-científico, pluridisciplinar, sociocultural e didáticopedagógico. Esses ajustes foram publicados no livro de Mendes e Chaquiam (2016) História nas aulas de Matemática: fundamentos e sugestões didáticas para professores, na segunda parte onde retrato "Um diagrama, um texto".

Em 2017 apresento sete exemplos de textos elaborados por alunos que tomaram o diagrama como balizador das escritas dos textos no livro Ensaios Temáticos: História e Matemática em sala de aula - disponível em www.ghemaz.com.br - a saber: Equação Quadrática: recorte da história das equações; Números Primos: uma história dos números; Conjuntos: sobre a história de sua evolução; Grandezas: uma história dos comensuráveis e incomensuráveis; Análise Combinatória: história para sala de aula; Trigonometria: recortes da história da sua evolução e Geometrias Euclidiana e Não-Euclidianas: composição histórica.

A seguir apresento o diagrama que têm sido objeto de estudos e pesquisas e considerações sobre cada um dos contextos que o compõe, bem como reflexões sobre o texto a ser elaborado a partir deste. 
Figura 1: Modelo do Diagrama-Metodológico

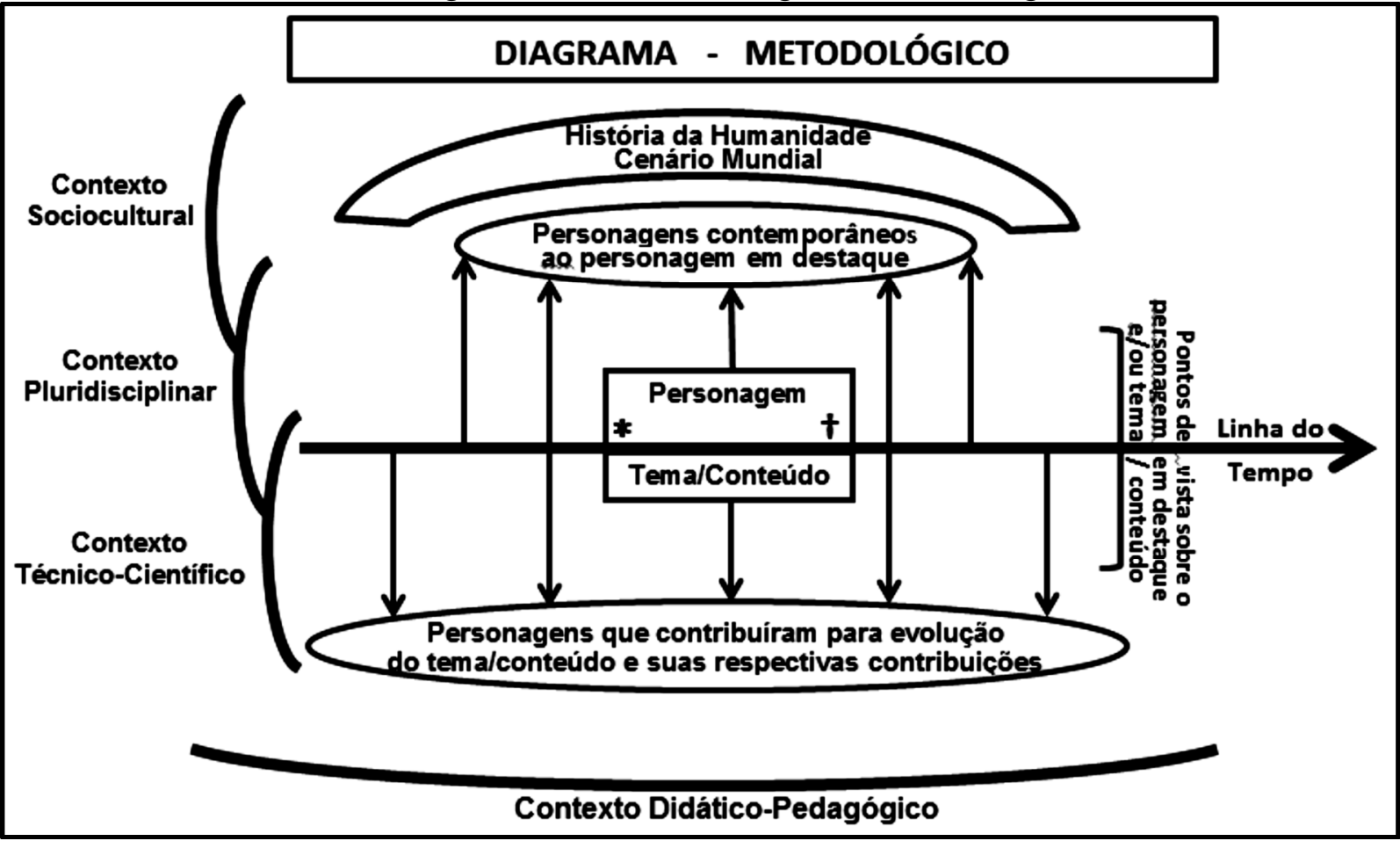

Fonte: Chaquiam (2017).

O diagrama é composto por três contextos principais: sociocultural, pluridisciplinar e técnico-científico. Esses contextos constituem as diferentes dimensões de abordagens pelos quais o tema/conceito pode ser trabalhado. O contexto técnico-científico abrange conceitos matemáticos, apresentados por meio de uma vertente teórico-prática, associada aos personagens que o conceberam numa ordem cronológica, dentre os quais é eleito um e, a partir deste, constituir os demais contextos - pluridisciplinar e sociocultural.

No contexto pluridisciplinar procura-se evidenciar o personagem eleito no contexto anterior por meio de seus contemporâneos oriundos das mais diversas áreas, onde são abordadas questões disciplinares, não necessariamente matemáticas, no sentido de caracterizar o que está ocorrendo nesses outros contextos científicos e seus personagens, perpassa por diferentes áreas do conhecimento, porém sua finalidade permanece inscrita ao contexto inicial. O contexto sociocultural contempla questões históricas e culturais mais abrangentes tendo em vista localizar o leitor a partir do personagem, eleito no contexto inicial, e de seus contemporâneos dentro do contexto pluridisciplinar. 
O contexto didático-pedagógico está relacionado à constituição do texto, ou seja, sugere-se que o texto deve ser elaborado a partir do contexto sociocultural, integrar o contexto pluridisciplinar, seguido do contexto técnico-científico e finalizado com a apresentação de outros pontos de vista mais recentes sobre o personagem destacado ou sobre o conteúdo matemático abordado e, sem separado, apresentar um conjunto de atividades que possam ser exploradas em sala de aula a partir do texto elaborado. Uma descrição mais detalhada pode ser obtida em Chaquiam (2017), disponível na Biblioteca em Educação Matemática da Sociedade Brasileira de Educação Matemática (SBEM) - www.sbembrasil.org.br/sbembrasil/.

\section{EXEMPLOS E AVALIAÇÃO DA EMPIRIA}

A evolução dessa proposta e exemplos pode ser constatada em Chaquiam (2015), Mendes e Chaquiam (2016) e Chaquiam (2017). Os exemplos apresentados nesse ínterim evidenciam a evolução do diagrama e a integração de novos elementos a este, bem como, profundidade dos textos elaborados pelos alunos da graduação e pós-graduação.

Dentre os problemas identificados durante a apresentação da proposta e constituição do diagrama destacam-se o desinteresse inicial dos alunos em relação ao uso da história da matemática no ensino de matemática - muito provavelmente gerada pela falta de aproximação destes com a história geral, principalmente com a história da matemática - e a pouca experiência quanto à elaboração de textos que desviar-se das características dos livros técnicos de matemática.

Pode-se afirmar que os primeiros diagramas apresentavam poucos personagens, tanto para caracterizar a evolução do tema quanto para caracterizar outros campos da ciência, bem como episódios relacionados à história geral dentro do recorte temporal estabelecido dissociado do apresentado nos contextos pluridisciplinar e técnico-científico, além disso, os textos finais apresentavam pouca integração entre os contextos indicados no diagrama.

As empirias foram realizadas ao longo do desenvolvimento das disciplinas História da Matemática e História da Matemática como recurso didático, respectivamente, no curso de licenciatura em Matemática e no Programa de Mestrado Profissional de Ensino de Matemática, como parte dos seus conteúdos programáticos. 
O diagrama a seguir foi elaborado a partir do tema "Números Negativos", em 2019, onde se sobressai ao longo da linha do tempo a quantidade de personagens envolvidos com a temática, bem como, o número de contemporâneos do personagem destacado Colin MacLaurin (1698 - 1746). Esse é um dos resultados da proposta apresentada por Chaquiam (2017), no Programa de Mestrado Profissional em Ensino de Matemática, onde se fez uso de um diagrama para balizar a elaboração de um texto que envolve história e matemática.

Figura 2: Diagrama - Números Negativos

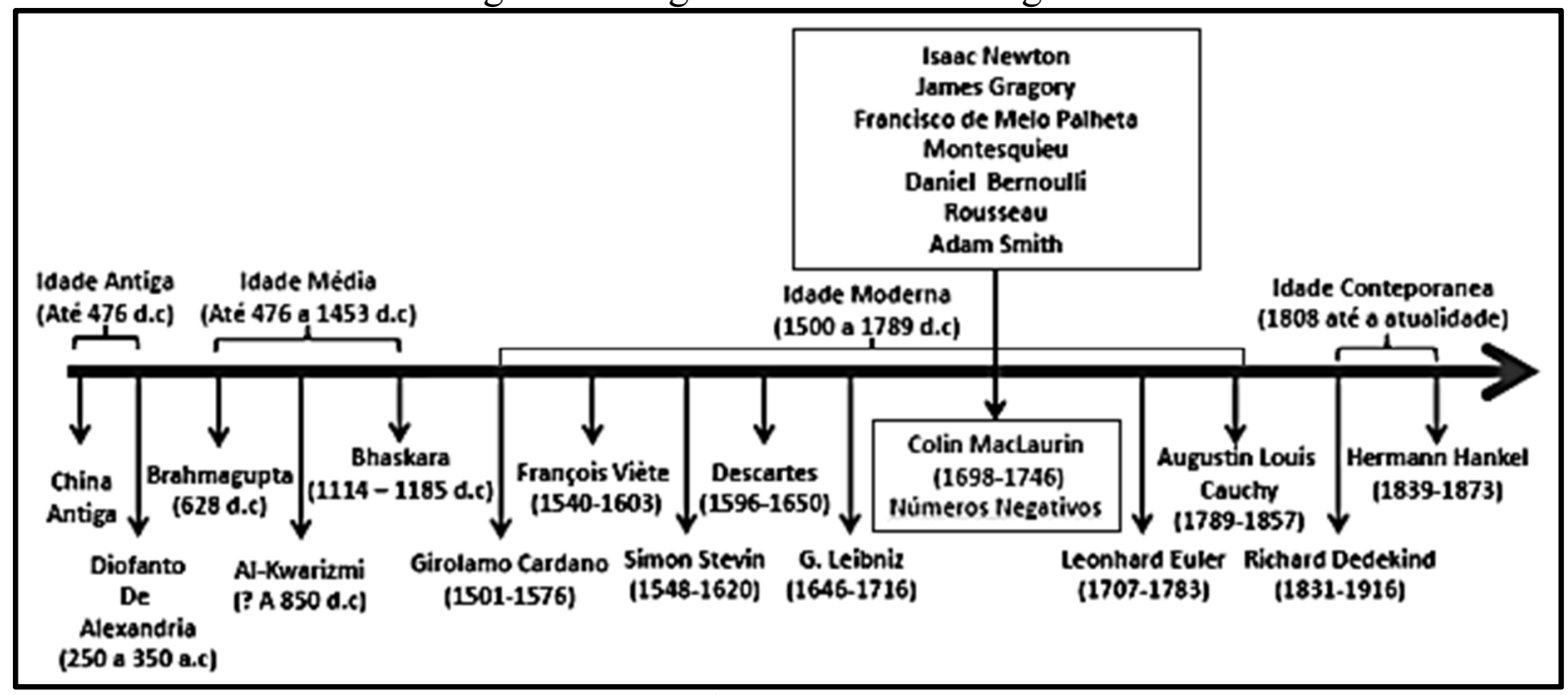

Fonte: Vasconcelos e Santos ${ }^{1}$, adaptado de Chaquiam (2017), 2019.

Iniciam-se as referidas disciplinas apresentando as diversas possibilidades de uso da história da matemática constantes nas literaturas mais recente e posteriormente, ampla discussão e análise dos diagramas e textos produzidos em anos anteriores. As reflexões a partir desses cenários contribuem de forma eficaz à produção de diagramas que contemplam uma maior diversidade e profundidade de elementos e personagens. Além das disciplinas, os trabalhos de conclusão de curso em licenciatura em Matemática tem gerado textos que podem ser utilizados em sala de aula.

Dentre os trabalhos conclusos, destacam-se os trabalhos de Lucas Antonio Mendes de Lima e Mayara Gabriella Grangeiro Pereira, intitulado "História da Matemática: Contribuições para o ensino de funções, equação quadrática e matrizes", 2017, e de Jessie

\footnotetext{
${ }^{1}$ Akilson Medeiros Vasconcelos e Francisco Nordman Costa Santos - alunos do Programa de Mestrado Profissional em Ensino de Matemática da Universidade do Estado do Pará.
} 
Heveny Saraiva Lima, intitulado “A História da Matemática no Ensino de Matemática: O caso da trigonometria", 2019.

Do primeiro trabalho resultaram dois trabalhos publicados em eventos científicos, a saber: Uma história do conceito de função para uso em sala de aula, no XII Seminário Nacional de História da Matemática (2017) e Equação Quadrática: um recorte histórico, no XI Encontro Paraense de Educação Matemática (2017), e um artigo publicado no Boletim Cearense de Educação e História da Matemática (2018), intitulado Uma abordagem histórica de matrizes para o uso em sala de aula.

Do segundo, três artigos em eventos científicos, a saber: A TRIGONOMETRIA NA GRÉCIA ANTIGA: Arquimedes, Eratóstenes, Apolônio e Hiparco de Nicéia, no XVIII Seminário Nacional de História da Matemática (2019); As contribuições à trigonometria nos séculos XVII, XVIII E XIX, no XVIII Encontro Nacional de Educação Matemática (2019) e Trigonometria: Al-Battani, Bhaskara Akaria, Fibonacci e Nicoled' Oresme, no XII Encontro Paraense de Educação Matemática (2019).

No decorrer das empirias foram efetuadas pesquisas para saber a visão dos participantes antes de terem cursarem as disciplinas supracitadas e sobre a utilização da história da matemática como recurso didático, particularmente o diagrama, em suas atividades profissionais ou acadêmicas.

A visão dos alunos em relação ao uso da história da matemática pode ser evidenciada ao responderem o seguinte questionamento: Antes de cursar História da Matemática, qual era sua visão sobre essa disciplina? Visto de cerca de $60 \%$ dos respondentes afirmaram que viam a disciplina constituída apenas por leituras que envolviam a história dos conteúdos e personagens. Por outro lado, cerca de 30\% não consideram a história da matemática um elemento importante para o ensino de matemática. Essas afirmações estão em consonância as respostas dos $73 \%$ que dizem não fazer uso da história da matemática em suas atividades acadêmicas ou profissionais antes de terem cursado uma das disciplinas citadas.

Quando a totalidade dos respondentes afirma que o diagrama é um meio viável para elaboração de textos que envolvem história e matemática, descortina-se a fragilidade destes quanto a organização de textos desta natureza, bem como, a pouca aproximação que possuem em relação a história da matemática de um modo geral. 
Cerca de $70 \%$ dos respondentes apontam ter tido dificuldades em obter informações para composição dos elementos constitutivos do diagrama metodológico em decorrência da escassez de referenciais teóricos ou materiais didáticos que abordem a história de conteúdos matemáticos, suas transformações e personagem contribuintes. Salientam que há pouca literatura disponível contemplando especificamente o uso da história da matemática em sala de aula.

Os respondentes afirmaram que o diagrama foi elemento primordial para a constituição do texto envolvendo os elementos indicados nos diversos contextos, que serviu de guia segundo cerca de $90 \%$ dos respondentes, embora tenham tido dificuldades de relacionar a história da matemática com os conteúdos matemáticos e a elaboração de atividades que explorem o texto produzido.

Quase a totalidade dos respondentes afirmou que essa abordagem da história da matemática por meio do diagrama contribuiu à sua formação acadêmica ou profissional, proporcionou maior compreensão de como utilizar a história da matemática como um recurso didático, trouxe novas perspectivas quanto a importância do uso da história da matemática no ensino e melhor compreensão das transformações ocorridas na matemática ao longo dos anos.

\section{CONCLUSÃo}

Essa proposta é uma das muitas pesquisas que procuram relacionar a história da matemática e o ensino de matemática, o diagrama pode ser considerado um meio de se organizar e integrar história e matemática por meio dos diversos contextos, bem como proporcionar melhor compreensão das origens das ideias matemáticas que temos hoje, observar os diversos aspectos de seu desenvolvimento e perceber que as teorias que hoje aparecem prontas e acabadas vieram de grandes esforços e desafios enfrentados por muitos ao longo dos tempos.

Em relação à formação inicial de professores de matemática, essa forma de pesquisa tem se demonstrado um meio eficaz para aproximar os alunos com a história da matemática, desmistificar que história da matemática está restrita a nomes, datas e fatos, além de proporcionar melhoria quanto a elaboração de textos que envolvem história e matemática.

Os resultados da utilização desse modelo metodológico apontam sua eficácia, os textos apresentam maior integração da história e com a matemática, apresentam-se cada vez mais 
consistentes e harmoniosos, entretanto, ainda faltam maiores aprofundamentos no que tange a elaboração de atividades abordando a temática e seu uso em sala de aula.

A proposta descrita não está endereçada aos historiados de profissão ou matemáticos com experiência em história da matemática, pode não ser uma forma muito significativa de bordar a história sob o ponto de vista de historiadores de ofício numa perspectiva atualizada, entretanto, orienta a elaboração de um texto que contempla uma abordagem multicontextual, proporciona a integração da história e matemática e fornece uma visão global aos iniciantes da historicidade do conhecimento científico.

Formatada inicialmente dentro de uma visão historiográfica tradicional, procura-se distanciar-se da visão presentista e evolucionista, aproximar-se de vertentes historiográficas mais atualizadas, embora não seja objetivo identificar as ideias iniciais, rastreá-las, analisar suas influências ou caracterizar onde se tornaram obstáculos nos desenvolvimentos subsequentes, mas, agregar trabalhos realizados por especialistas que apresentem tais fatos e, a partir destes, selecionar recortes de modo que possam ser explorados dentro de um contexto didático-pedagógico como recurso didático.

Considerando as similaridades entre a história da matemática e a história de outras áreas do conhecimento científico, dentre elas, física, química e biologia, entende-se que é possível adequar o diagrama proposto a essas outras áreas, bem como elaborar textos que integrem a história dessas áreas aos conteúdos específicos de cada área.

\section{REFERENCIAS}

CHAQUIAM, M. Uso e Implicações das Linguagens no Ensino de Matemática. Coleção Educação Matemática na Amazônia, v. 4. Belém: SBEM-PA, 2015.

CHAQUIAM, M. História da matemática em sala de aula: proposta para integração aos conteúdos matemáticos. Natal: Livraria da Física, 2015.

CHAQUIAM, M. Um diagrama, um texto. In: MENDES, I. A. \& CHAQUIAM, M. História nas aulas de Matemática: fundamentos e sugestões didáticas para professores. Belém: SBHMat, 2016, p. 77 - 125.

CHAQUIAM, M. Ensaios Temáticos: História e Matemática em sala de aula. Belém: SBEM-PA, 2017.

MENDES, I. A. História da Matemática no Ensino: Entre trajetórias profissionais, epistemologias e pesquisas. São Paulo: Livraria da Física, 2015. 
MENDES, I. A. \& CHAQUIAM, M. História nas aulas de Matemática: fundamentos e sugestões didáticas para professores. Belém: SBHMat, 2016.

MENDES, I, A. O uso da história no ensino da Matemática: reflexões teóricas e experiências. Belém (PA): EDUEPA, 2001.

MOURA, Breno Arisoli; SILVA, Cibelle Celestino. A abordagem Multicontextual da História da Ciência na Formação de Professores de Física: análise de um estudo de caso. Revista Brasileira de História da Ciência, Rio de Janeiro, v. 7, n. 2, p. 336-348.

DIAS, Marisa da Silva; SAITO, Fumikazu. Interface entre História e Ensino de Matemática: Aspectos Teóricos e Metodológicos. In. Actas del VII CIBEM. Pp. 7502 - 7509. ISSN 23010797. Montevideo, setembro, 2013.

DIAS, Marisa da Silva; SAITO, Fumikazu. Interface entre História da Matemática e Ensino: uma atividade desenvolvida com base num documento do século XVI. In. Ciência \&Educação, v. 19, n. 1, p. 89-111, 2013.

Autor

Miguel Chaquiam

Doutor em Educação pela Universidade Federal do Rio Grande do Norte (2012). Mestre em Matemática pela Universidade Federal do Pará (2001). Licenciado em Matemática pelo Centro de Estudos Superiores do Estado do Pará (1984). Atualmente é professor da Universidade do

Estado do Pará (UEPA/PA/Brasil) e pesquisador do Programa de Mestrado Profissional em Ensino de Matemática (PMPEM/UEPA). Tem experiência na área de Matemática, com ênfase em Matemática Computacional, Álgebra Linear; Estruturas Algébricas, Análise Real, História da Matemática, História das Ciências e Formação de Professores. Líder do Grupo de Pesquisa em História, Educação e Matemática na Amazônia (GHEMAZ). Tem interesse Matemática,

Ensino de Matemática e História da Matemática. Mais informações no Currículo Lattes: http://lattes.cnpq.br/9356361533701895. ORCID: https://orcid.org/0000-0003-1308-8710. Email: miguelchaquiam@gmail.com. 